ISSN: 2231-3354

Received on: 21-06-2012

Revised on: 09-07-2012

Accepted on: 18-07-2012

DO: 10.7324/J APS.2012.2725

Harshada Sanjay Akre, Dharmendra

R. Munchaca, Shyamala Bhaskaran, Gopal Satishkumar Gandhi

A gni hotri College of P harmacy, Wardha, Indi a.

\section{Sohail Asghar}

Product Development M anager, Unijules LifeSciences LTD, Kalmeshwar,
For Correspondence Harshada Sanjay Akre Agni horri College of pharmacy, AGl Campus, Bapuji wadi, Ram nagar, Sindhi (M eghe), Wardha 442001, I ndia.

Phone 7387864310

\section{Dry Suspension Formulation of Taste Masked Antibiotic Drug for Pediatric Use}

\author{
Harshada Sanjay Akre, Dharmendra R. Mundhada, Shyamala Bhaskaran, \\ Sohail Asghar and Gopal Satishkumar Ganchi
}

Keywords: Dry suspension, Taste Masking, Macrolide Antibiotic, Eudragit L 100.

\title{
INTRODUCTION
}

Clarithromycin (6-0-methyl-erythromycin A) is a 14-membered macrolide antimicrobial agent widely used for treatment of infections such as respiratory infection, skin soft tissue infection, Chlamydia infection and helicobacter pylori infection and so on. It is also clinically active against bacteria responsible for exacerbations of chronic bronchitis and the atypical pathogens that cause respiratory tract infections. Clarithromycin is stable in the gastric acid and well absorbed, but it has a very bitter taste, this make it inconvenient when taken orally. Also used to treat pharyngitis, tonsillitis, acute maxillary sinusitis, acute bacterial exacerbation of chronic bronchitis, pneumonia (KD Tripath, 2003). Clarithromycin prevents bacteria from growing by interfering with their protein synthesis. Clarithromycin binds to the subunit 50S of the bacterial ribosome and thus inhibits the translation of peptides. EUDRAGIT® L 100(Degussa, 2009) is anionic copolymers based on methacrylic acid and methyl methacrylate. It is a solid substance in form of a white powder with a faint characteristic odour. It has effective and stable enteric coatings with a fast dissolution in the upper bowel. Granulation of drug substances in powder form for controlled release can be used. Site specific drug delivery in intestine by combination with EUDRAGIT $^{\circledR} \mathrm{S}$ grades also shows variable release profiles. 
Clarithromycin is a highly bitter taste drug and also it shows the problem of hydrolysis when it is in liquid formulation. This will affect the stability of the suspension and potency of the drug. The purpose of this work is to develop a dry suspension powder from which a permanent stable suspension can be prepared after reconstitution.

\section{MATERIALS AND METHODS}

\section{Materials}

Clarithromycin, Eudragit L100 was procured from Merck Company Mumbai. Excipients used for preparation of suspension are Sucralose, Aerosil, citric acid, sugar, xanthan gum and colourquinidine yellow were also procured from Merck Company Mumbai.

\section{Compatibility studies (Beckett et.al, 1993)}

\section{Fourier transforms infrared spectroscopy (FTIR) analysis}

Drug and polymer were mixed in ratio of $1: 1$ and mixtures were placed in sealed vials for 3 months at room temperature. FTIR measurement of drug and individual polymer and drug polymer mixture were obtained on Simadzu FTIR. Samples were prepared with Kbr and placing in sample holder. The spectra were scanned over the wave number range of $4000-400 \mathrm{~cm}^{-1}$ at the ambient temperature.

Preparation of Clarithromycin microspheres (Lachman et.al, 1990)

Taken Acetone required to disperse the accurately weighed quantity of polymer Eudragit L100 in it. Stirred for few min and then added weighted quantity of Clarithromycin, stirred for 10-15 min with $4000 \mathrm{rpm}$ to ensure uniform dispersion of drug particles. Transferred the microcapsule in tray and allowed drying on room temperature for 24 hours to ensure complete evaporation of acetone. Microcapsules were crushed and then passed through sieve \# 80 to get the uniform, free flowing and discreet particles. The microcapsules were separately prepared using polymer Eudragit L100 in Drug: Polymer ratio 1:1, 1:2, 1:3, 1:4 and 1:5 following the same procedure. Drug proportion was maintained constant so as to determine maximum polymer required to encapsulate drug, and to obtain desired drug release.

\section{Evaluation of microcapsules}

Particle size and morphology evaluation (Martin Alfred, 1994)

Optical microscope was used to evaluate both the morphology and surface characteristics of the microcapsules.

\section{Micromeritic properties (Fonner et.al.1993)}

The granule size separation was carried out by vibrating sieve shaker at medium vibration level for $20 \mathrm{~min}$ using five standard sieves of \#8 $(2360 \mu \mathrm{m})$ to \#200 $(75 \mu \mathrm{m})$. Undersize fractions (fines collected in collector was excluded) were then collected, stored in a desiccators at $25 \pm 2{ }^{\circ} \mathrm{C}$ and used for the dissolution studies. Powder properties of all preparations were measured using tap density tester.

\section{Drug loading rate and entrapment rate}

Validation of the optimized HPLC method was carried out with respect to the following parameters.

\section{Chromatographic conditions}

The HPLC separation was performed using a methanol as a mobile phase, consisting of potassium dihydrogen phosphate (KDP, $0.067 \mathrm{~mol} / \mathrm{l}$ ) acetonitrile (35:65), was delivered at a flowrate of $1.0 \mathrm{ml} / \mathrm{min}$; Detection was set at $220 \mathrm{~nm}$ and the column temperature was maintained at $50^{\circ} \mathrm{C}$. Stop time 15.0 mins.

\section{Standard Calibration Curve of Clarithromycin:}

Preparation of working solution for standard calibration curve A $10 \mathrm{ml}(1000 \mu \mathrm{g} / \mathrm{ml})$ of stock solution was diluted to $100 \mathrm{ml}$ with methanol to get $100 \mu \mathrm{g} / \mathrm{ml}$ solutions. From above mentioned working standard solution, aliquots was taken and then diluted up to $10 \mathrm{ml}$ with methanol to get $10-100 \mathrm{ug} / \mathrm{ml}$.

\section{Sample analysis}

Weighted $80 \mathrm{mg}$ of microcapsules accurately, dissolved $20 \mathrm{ml}$ of mobile phase using the ultrasound, transfered the content to $50 \mathrm{ml}$ volumetric flasks and make up the volume with mobile phase. Filtered sample with $0.2 \mathrm{u}$ filter paper and used the filtrate for further analysis. Taken $20 \mu \mathrm{l}$ of filter liquor accurately, injected and calculated the content (Liandong Hu et.al, 2011).

\section{Drug Loading =}

Weight of the drug loaded in a microcapsule X 100 The total weight of microcapsules

\section{Microencapsulation Efficiency =}

Estimated percent drug content X 100

Theoretical percent drug content

The pure drug and taste masked microcapsules was compared for its taste and from that it is decided whether the taste of the drug is to be masked or not.

\section{Percent Production Yield}

The percentage production yield of the produced microcapsule can be calculated for each batch by dividing the weight of microcapsule (M) by the total expected weight of drug and polymer $(\mathrm{Mt})$.

$\%$ Production Yield $=\mathrm{M} / \mathrm{Mt}$

\section{In Vitro Dissolution Testing}

The USP apparatus 1 (rotating basket) set to sink conditions has been used to study in vitro drug release. Microcapsules equivalent to $500 \mathrm{mg}$ of Clarithromycin were placed in basket of dissolution test apparatus in $0.1 \mathrm{~N} \mathrm{HCL}$ sink condition for 2 hours. Dissolution medium was maintained at $37 \pm 0.5$.After 2 hours $900 \mathrm{ml}$ of phosphate buffer 6.8 was replaced and used to carry out dissolution with the basket at $100 \mathrm{rpm} .5 \mathrm{ml}$ of aliquots were withdrawn by single mark pipette after every $30 \mathrm{~min}$ interval and volume withdrawn was replaced with fresh equal quantities of 
fluid. Taken filter liquor and make sufficient dilution and determined for the drug release by HPLC and then calculated accumulative drug release (Sandile et. al.2009).

\section{Formulation of Dry Suspension of Clarithromycin}

Microcapsules of optimized ratio i.e. 1:3 were selected to formulate dry suspension. Dry suspension was formulated as per following formula (Table. 1) all ingredients were passed through $40 \#$ sieve. The smallest amount of drug is mixed with same amount of other excipients.. All the ingredients were mixed thoroughly flavour was added at the end. The dry suspension which is formed is reconstituted up to $30 \mathrm{ml}$ with distilled water before use (Hirali K Shah etal., 2010).

Table. 1: List of excipients used for formulation of suspension.

\begin{tabular}{ll}
\hline \multicolumn{1}{c}{ Ingredients } & Weight $\mathbf{( g m )}$ \\
\hline Complex & 3.01 \\
Sucralose & 0.045 \\
Aerosil & 0.090 \\
Citric acid & 0.071 \\
Xanthan gum & 0.096 \\
Color (quinidine yellow) & 0.0040 \\
Sugar upto & Qs to17gm \\
\hline Each formulation is equivalent to 0.75 gm of Clarithromycin. $5 \mathrm{ml}$ of suspension \\
contain 125 mg of Clarithromycin.
\end{tabular}

\section{Evaluation of dry suspension}

\section{Assay for Drug content}

Sample solution:

Taken $3.45 \mathrm{~g}$ of sample (Clarithromycin suspension) which is equivalent to $3.0 \mathrm{ml}$ in $50 \mathrm{ml}$ beaker, added $20 \mathrm{ml}$ of mobile phase and stirred for 30 minutes to dissolve, transferred the content to 50 $\mathrm{ml}$ volumetric flasks and made up the volume with mobile phase, filtered with $0.2 \mathrm{u}$ filter paper and used the filtrate for further analysis.

Chromatographic condition:

- Mobile phase

- Methanol: 0.2M KH2PO4 (35:65)

- $\lambda \max$

- 220nm

- Temperature

$-50{ }^{0} \mathrm{C}$

- Flow rate

$-1.0 \mathrm{ml} / \mathrm{min}$

- Stop time

$-15.0 \mathrm{~min}$

\section{Sedimentation Volume}

The sedimentation volumes were determined by keeping $50 \mathrm{ml}$ of each suspension in stopper measuring cylinder and stored undisturbed at room temperature. The separation of clear liquid was noted at intervals of 1 day and up to 14 days.
The sedimentation volume $F$ was calculated using the formula $F=V \mathrm{u} / V_{\mathrm{o}}$, where $V \mathrm{u}$ is the volume of sediment and $V_{\mathrm{o}}$ is the original height of the sample.It is expressed as a percentage (Sateesha et.al, 2010).

Degree of flocculation ( $\beta$ ) (Gohle et.al, 2007)

$$
\begin{array}{ll}
\beta= & \mathrm{F} / \mathrm{F} \infty \\
= & \frac{\mathrm{V}_{\mathrm{u}} / \mathrm{Vo}_{\mathrm{o}}}{\mathrm{V} \infty / \mathrm{V}_{\mathrm{o}}} \\
= & \mathrm{Vu} / \mathrm{V}_{\infty}
\end{array}
$$

$=$ Ultimate sediment volume fo flocculated suspension Ultimate sediment volume fo deflocculated suspension

Stability studies (Kulkarni et.al, 2004)

\section{Drug content determination}

The chemical stability of Clarithromycin is important because the physicochemical characteristics of Clarithromycin depended on excipients employed in preparation. Hence the preparations was subjected for stability studies. The stability of Clarithromycin was assessed by evaluating the percentage of the initial concentration remaining after specific period of time under different conditions. A difference in concentration by $\pm 10 \%$ was considered a notable change in drug stability.

\section{pH measurements}

Change in $\mathrm{pH}$ of the suspension followed by reconstitution was measured for all the formulations using a digital $\mathrm{pH}$ meter on day 1 and day 14 at $25^{\circ} \mathrm{C}$.

\section{Comparison with marketed preparation}

In vitro release of prepared suspension and marketed preparation is compared. The condition for the dissolution study is same as that of microcapsule.

\section{RESULTS AND DISCUSSION}

\section{FTIR Studies}

When IR of Clarithromycin (Fig 1) was correlated with physical mixture of drug and excipients (Fig 2) the region of 3410 $\mathrm{cm}^{-1}$ was found due to the $\mathrm{N}-\mathrm{H}$ (aromatic) stretching. However other peaks related to $\mathrm{C}-\mathrm{H}, \mathrm{C}-\mathrm{O}$ and carbonyl stretching remain unchanged (Table No. 2). This indicates that overall symmetry of the molecule might not be significantly changed, therefore the FTIR study revealed that there is no interactions taking place between

\begin{tabular}{|c|c|c|}
\hline Material & Functional group & FT-IR signalling $\left(\mathrm{cm}^{-1}\right)$ \\
\hline \multirow{4}{*}{ Clarithromycin } & Tertiary $-\mathrm{N}$ stretching. & 3468 \\
\hline & Carbonyl stretching & 1734 \\
\hline & Aliphatic-CH stretching. & 1172 \\
\hline & Hydroxyl $(\mathrm{OH})$ stretching. & 2941 \\
\hline \multirow{4}{*}{ Clarithromycin and Eudragit $L 100$ complex } & Tertiary-N stretching (aromatic). & 3410 \\
\hline & Carbonyl stretching & 1734 \\
\hline & Aliphatic $-\mathrm{CH}$ stretching. & 1172 \\
\hline & Hydroxyl $(\mathrm{OH})$ stretching & 2941 \\
\hline
\end{tabular}
Clarithromycin and Eudragit L100.

Table. 2: FT-IR study of Clarithromycin and Physical mixture of Clarithromycin -Eudragit L100. 


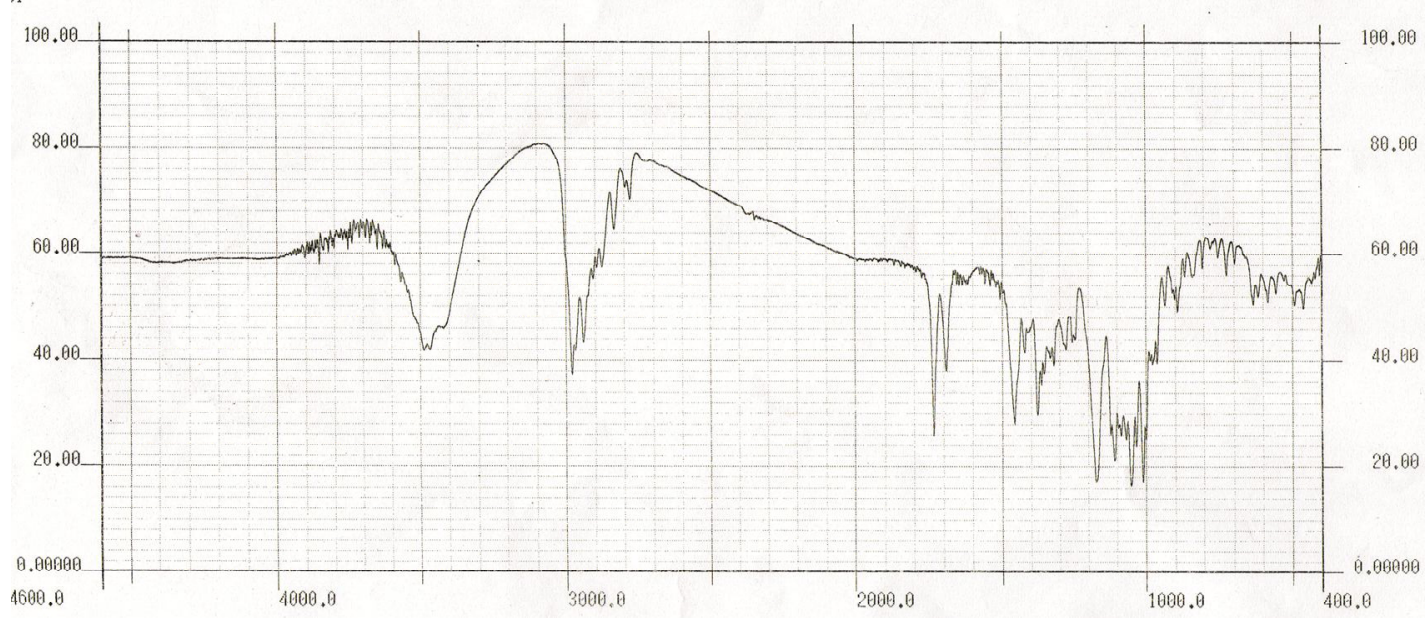

Fig. 1: IR Spectrum of Clarithromycin.

\%T

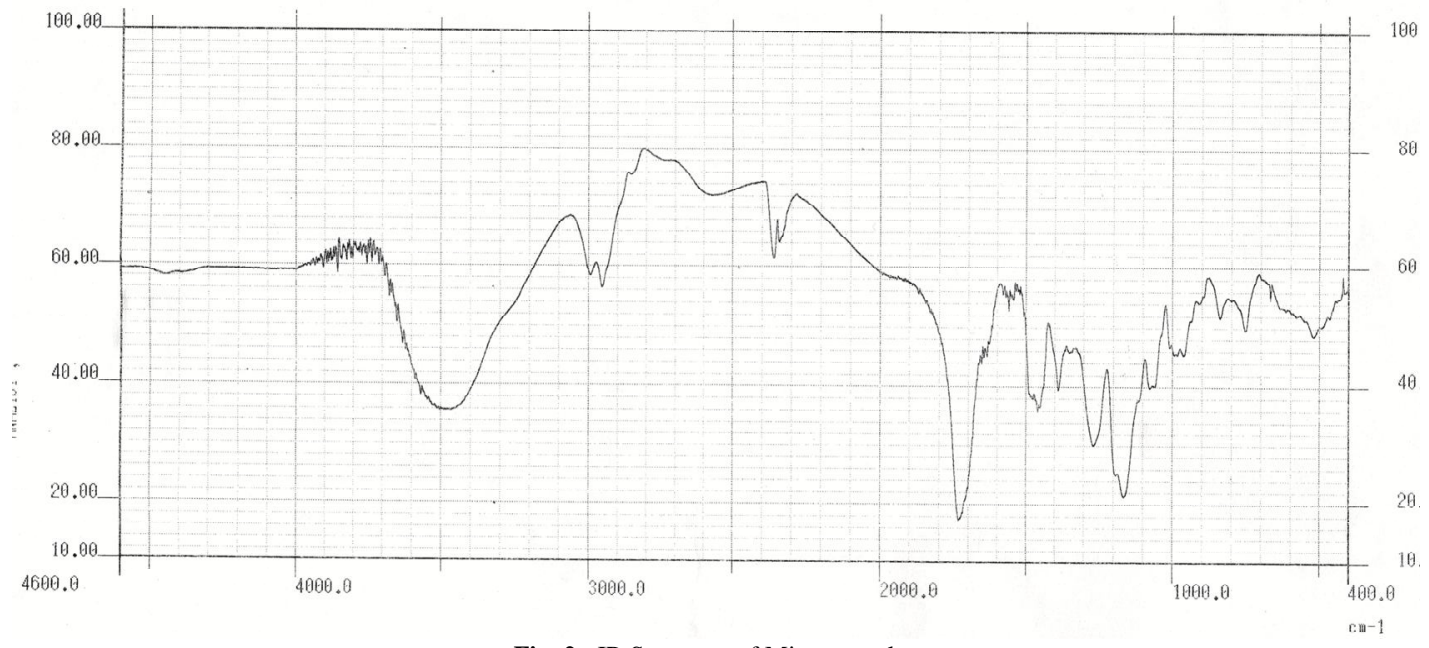

Fig. 2: IR Spectrum of Microcapsules

\section{Standard calibration curve of Clarithromycin}

Clarithromycin was found to be soluble in organic solvents such as methanol. HPLC method of estimation was carried out in methanol ranging from $10-100 \mathrm{mcg} / \mathrm{ml}$ solutions at $220 \mathrm{~nm}$ against the blank. The standard graph obtained was linear, with regression coefficient 0.999as indicated in (Fig 3).

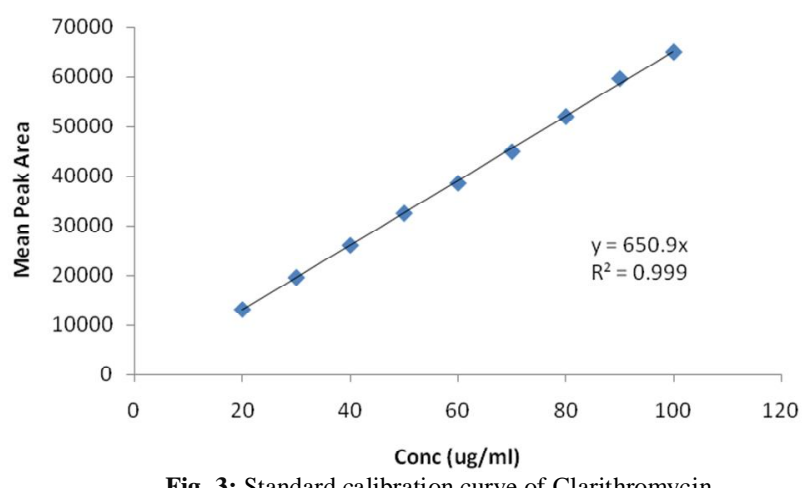

Fig. 3: Standard calibration curve of Clarithromycin.

\section{Evaluation of Microcapsules}

It can be observed from the (Table 3 )that all the batches of microcapsules have bulk density are less than $1.2 \mathrm{gm} / \mathrm{cm}^{3}$ and angle of repose less than $40^{\circ} \mathrm{C}$ indicates good flow properties.

Table. 3: Physical property of microcapsules

\begin{tabular}{ccc}
\hline $\begin{array}{c}\text { Ratio Clarithromycin : Eudragit } \\
\text { L 100 }\end{array}$ & $\begin{array}{c}\text { Bulk density } \\
\left(\mathbf{g m} / \mathbf{c m}^{\mathbf{3}}\right)\end{array}$ & $\begin{array}{c}\text { Angle of } \\
\text { Repose }\end{array}$ \\
\hline $1: 1$ & $0.33 \pm 0.010$ & $30.30 \pm 0.11$ \\
$1: 2$ & $0.32 \pm 0.012$ & $29.52 \pm 0.22$ \\
$1: 3$ & $0.34 \pm 0.016$ & $27.54 \pm 0.12$ \\
$1: 4$ & $0.41 \pm 0.013$ & $31.53 \pm 0.21$ \\
$1: 5$ & $0.45 \pm 0.018$ & $26.80 \pm 0.18$ \\
\hline
\end{tabular}

\section{Percent Drug Loading, Encapsulation Efficiency and} Production Yield of Different Batches of Microcapsules

Drug content of prepared microcapsules was determined by procedure described earlier. The drug content of all 5 formulations and encapsulation efficiency of microcapsules and percentage production yield is tabulated in (Table 4). 
Table. 4: Percent Drug Content and Encapsulation Efficiency and Production Yield of Different Batches of Microcapsules

\begin{tabular}{cccc}
\hline $\begin{array}{c}\text { Ratio of Clarithromycin: } \\
\text { Eudragit L100 }\end{array}$ & $\begin{array}{c}\text { \% Drug } \\
\text { Loading }\end{array}$ & $\begin{array}{c}\text { Encapsulation } \\
\text { efficiency }\end{array}$ & $\begin{array}{c}\text { \% Production } \\
\text { Yield }\end{array}$ \\
\hline $1: 1$ & 42.80 & 85.6 & 95.34 \\
$1: 2$ & 29.56 & 88.68 & 96.56 \\
$1: 3$ & 23.15 & 92.60 & 97.56 \\
$1: 4$ & 18.88 & 94.4 & 99.98 \\
$1: 5$ & 9.85 & 96.20 & 97.21 \\
\hline
\end{tabular}

\section{In Vitro Drug Release Profile}

The drug release profiles of different batches of microcapsules were studied in phosphate buffer 6.8. The results obtained for different of microcapsules are tabulated in following. (Table 5). From the (Fig 4) it was found that microcapsules of 1:3 ratio show better release with excellent taste masking with minimum concentration of Eudragit L100. Hence 1:3 batch was selected for formulation of dry suspension.

Tables. 5: In vitro release profile of microcapsules.

\begin{tabular}{|c|c|c|c|c|c|}
\hline \multicolumn{2}{|c|}{ Time in min } & \multicolumn{4}{|c|}{$\begin{array}{c}\text { \% drug release of microcapsules of } \\
\text { different Ratios }\end{array}$} \\
\hline & $1: 01$ & $1: 02$ & $1: 03$ & $1: 04$ & $1: 05$ \\
\hline $\mathbf{0}$ & 0 & 0 & 0 & 0 & 0 \\
\hline 30 & 6.01 & 6.34 & 5.9 & 5.6 & 5 \\
\hline 60 & 17.25 & 15.24 & 14.99 & 18.67 & 15.67 \\
\hline 90 & 34.29 & 26.78 & 22.87 & 25.23 & 21.98 \\
\hline 120 & 45.29 & 39.24 & 32.67 & 29.45 & 24.98 \\
\hline 150 & 54.34 & 45.23 & 47.86 & 39.87 & 31.37 \\
\hline 180 & 62.78 & 52.98 & 55.45 & 45.29 & 39.45 \\
\hline 210 & 67.69 & 65.26 & 64.67 & 50.35 & 45.68 \\
\hline 240 & 79.35 & 78.93 & 70.45 & 53.68 & 49.76 \\
\hline 270 & 83.68 & 82.45 & 75.34 & 58.49 & 52.69 \\
\hline 300 & 90.34 & 86.79 & 79.26 & 60.45 & 56.78 \\
\hline 330 & 87.45 & 85.23 & 83.67 & 60.48 & 53.64 \\
\hline 360 & 87.56 & 86.41 & 85.56 & 61.45 & 55.16 \\
\hline 390 & 87.91 & 87.34 & 85.91 & 62.43 & 55.67 \\
\hline 420 & 88.34 & 87.91 & 86.54 & 62.9 & 56.24 \\
\hline 450 & 89.01 & 88.3 & 87.24 & 63.5 & 56.82 \\
\hline
\end{tabular}

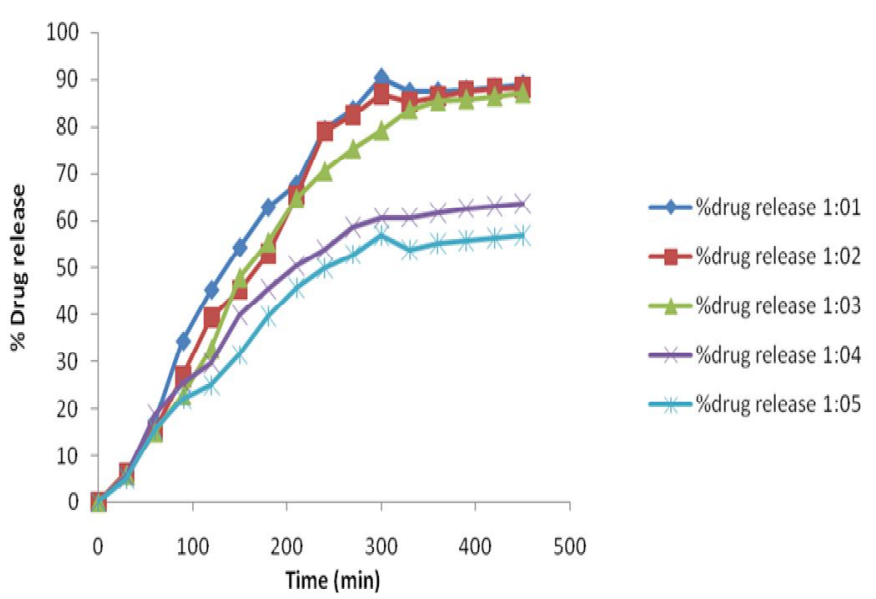

Fig. 4: In vitro drug release profile of five batches of microcapsules

\section{Optimization of Microcapsules}

From the in vitro release profiles of all the batches of microcapsules prepared with Eudragit L100 in ratio of 1:3 shows required rate of drug release. Also this batch showed encapsulation efficiency (92.60\%) (Table 4), it stood well in all physical evaluation parameters. Hence this batch was selected for further studies.

\section{Surface Characterization}

The microcapsules were scanned using scanning electron microscope. The scanning electron micrograph (SEM) of microcapsules showed that microcapsules were spherical in shape with the presence of rough porous polymeric film. (Fig $5 \mathrm{a} \& \mathrm{~b}$ ).
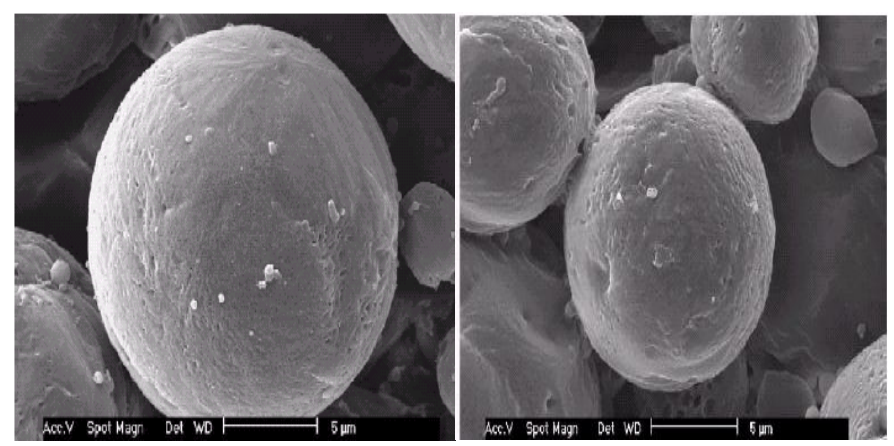

Fig. 5: Scanning Electron Micrograph of Optimized Microcapsules at $60 \mathrm{X}$ Magnification

\section{Evaluation of oral reconstitutable suspension}

Assay value of the suspension was found to be $97.73 \%$.

\section{Sedimentation volume}

From the figure it is observed that the sedimentation volume is between 1-0 at the end of 14 days, it shows good stability of suspension. The shape of curve shows good stability of suspension (Fig 6).

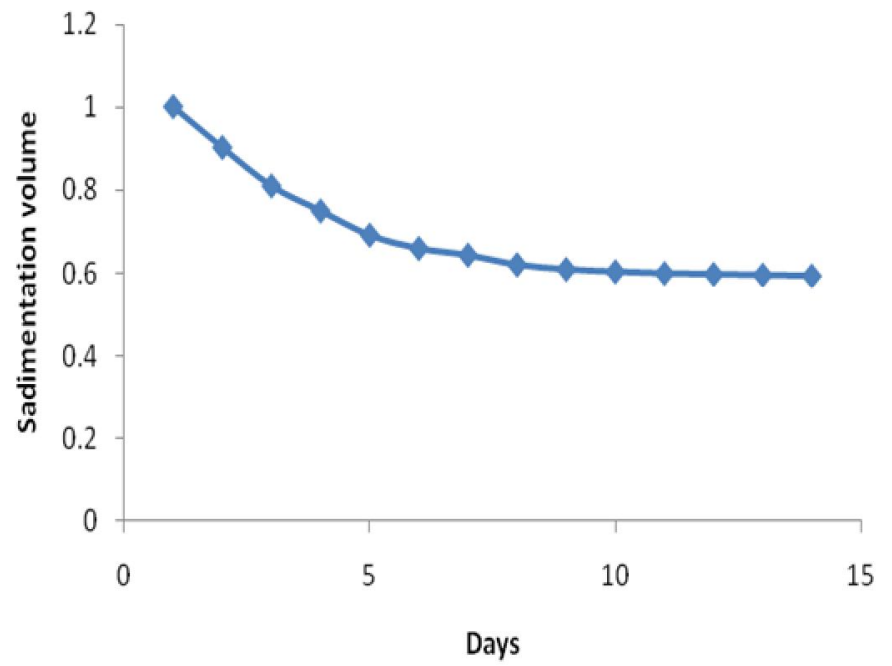

Fig. 6: Sedimentation Volume.

\section{Degree of flocculation}

$\boldsymbol{\beta}=28 / 25$

$\boldsymbol{\beta}=1.12$ Shows the greater stability.

If the $\boldsymbol{\beta}$ value is near to 1 , then the suspension does not represent a flocculated suspension. It indicates that the system under study is deflocculated system. But $\boldsymbol{\beta}$ can assume any value greater than 1.In general, the higher the value of $\mathrm{B}$, the greater is the physical stability. 


\section{Stability studies}

There is no significant change in $\mathrm{pH}$ and Drug content of suspension. The prepared formulation show good stability for 14 days (Table 6)

Table. 6: Physical properties of reconstituted Suspension of optimise batch

\begin{tabular}{ccc}
$\begin{array}{c}\text { Optimise batch formulation } \\
(\mathbf{1 : 3 )}\end{array}$ & $\begin{array}{c}\mathbf{p H} \text { of the formulation at } \\
\mathbf{2 5}^{\mathbf{0}} \mathbf{C}\end{array}$ & $\begin{array}{c}\text { Drug } \\
\text { content \% }\end{array}$ \\
\hline Day 1 & 4.42 & 95.04 \\
Day 14 & 4.40 & 93.09 \\
\hline
\end{tabular}

\section{Comparison with marketed preparation (Clarie)}

The release profile of prepared Clarithromycin suspension was better as compared to marketed suspension as shown in (Fig 7).

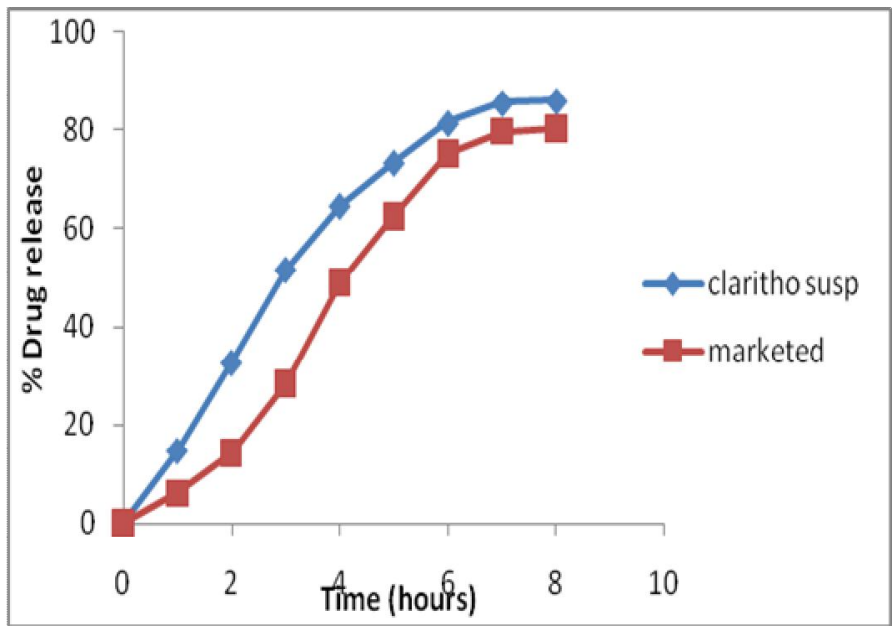

Fig. 7: In vitro release comparison with marketed preparation.

Table. 7: In vitro drug release of formulation compared with marketed preparation (Clarie).

\begin{tabular}{ccc}
\hline Time(hours) & Clarithromycin suspension & Marketed Suspension (Clarie) \\
\hline 0 & 0 & 0 \\
1 & 14.66 & 6.1 \\
2 & 32.67 & 14.1 \\
3 & 51.68 & 28.23 \\
4 & 64.67 & 48.9 \\
5 & 73.4 & 62.34 \\
6 & 81.45 & 75.13 \\
7 & 85.56 & 79.68 \\
8 & 85.97 & 80.23 \\
\hline
\end{tabular}

\section{CONCLUSION}

In present study microcapsules of Clarithromycin was prepared by using different ratios of Clarithromycin to Eudragit L100. Eudragit L 100 shows good taste masking property for Clarithromycin at 1:3 drug and polymer ratio. Also show better drug release profile for Clarithromycin. Prepared suspension of Clarithromycin shows better taste as compared to marketed preparation.

\section{REFERENCES}

Abuzarue Aloul R., Gjellan K., Sjolund M., Graffner C. "Critical Dissolution Tests of Oral Systems Based on Statistically Designed Experiments. I. Screening Of Critical Fluids and In Vitro/ In Vivo Modelling of Extended Release Coated Spheres", Drug Dev. Ind. Pharm. 1997; 23(8):749-760.

Beckett A.H., "Infrared Spectrophotometry", W.D. Williams, Edn. $3^{\text {rd }} ; 2 ; 331-339$. 2009;1-4.

Degussa, Specification and Test Methods for Eudragit L100,

Dr. Mukesh Gohle, Dr. Rajesh Parikh, Amirali Popat, Ashutosh Mohapatra,Bhaveash Barot,Chetan Patal, Hardik Joshi, Krishnakant Sarvaiya, Laigi Baldaniya, Pritesh Mistry, Punit Prejiya, Ramesh Parmar, Stavan Nagori ,Tushar Patel, 'Pharmaceutical Suspension: A Review, 2007:1-71.

Fonner D.E., Banker G.S., Swarbick I.I., "Micromeritics of Granular Pharmaceutical Solids", J. Pharm. Sci., 1993; 55; 181.

Hirali K Shah, Natalie Parfitt, Tsitsi Nayamuzhiwa, Hendrina Haidula, and Roderick B.Walker, " Formulation Development and Evaluation of Dipyridamole Dry Suspension Formulated Using Novel GalenIQ Polymer. Journal of Pharmacy Research, 2010;3(7):1499-1501.

KD Tripath, 'Essentials of Medical Pharmacology', 5th Ed., Jaypee Brothers Publishers, New Delhi,(2003):689.

Jain D.K.*, Darwhekar G.N., and Choudhary N. Formulation and Evaluation of Reconstitutable Oral Suspension of Ambroxol $\mathrm{HCl}$ and Azithromycin International Journal of PharmTech Research, 2011; 3(2):741-746.

Kulkarni G.T., Gowhamarajan K. and Suresh B., "Stability Testing of Pharmaceutical Products: An Overview", Indian J. Pharm. Education, 2004; 38(4): 194-202.

Kumar Sushanta and Madhav N.V.Stheesh, 'Masking Of Bitter Taste Of Clarithromycin By Microencapsulation Using Hydrophilic Polymers Blends And Their Evaluation. Journal of Global Pharma Technology, 2010; 2(6): 13-20.

Lachman L., Liberman H.A., Kanig J.L., "Theory and Practice of Industrial Pharmacy", Edn.3, Varghese Publishing House, Bombay, 1990; 427.

Liandong $\mathrm{Hu}$, Wei Liu, LiLI, Jiqianh Zhao and Xan Yang, 'Preparation and In Vitro, In Vivo Evaluation of Clarithromycin Microcapsules, Feb 2011,(2).1-9.

Martin Alfred, "Physical Pharmacy", Edn. 4th, B.I. Warely Pvt. Ltd. New Delhi, 1994; 430-431.

M. Maghsoodi, 'Physicomechanical Properties of NaproxenLoaded Microparticles Prepared from Eudragit L100, AAPS Pharm Sci Tech, 2009; 10(1); 120-128.

Prado.HJ. Siebel,C, 'Acrylic Polyelectrolytes As Taste Masking Agents In Oral Solution Dosage Forms'.

Sandile M. Khamanga,Nitalie Parfitt, TsitsiNamuzhiwa, Hendrina Haidula, and Roderick B. Walker, 'The Evaluation of Eudragit Microcapsules Manufactured by Solvent Evaporation Using USP Apparatus 1, Dissolution Technologies , 2009:15-21.

S.B. Sateesha, A.J.Rajamma, H.S.Shekar, R.K Mahammad Mutaar, A.Jayanthi, 'Formulation and stability study of palatable norfloxacin dry syrup: comparision among different preparation methods, Asian Journal of Pharmaceutical Sciences, 2010;5(5):175-184.

Vijay D. Wagh, Shyam V. Ghadlinge. 'Taste Masking Methods and Techniques in Oral Pharmaceuticals: Current Perspective. Journal of Pharmacy Research 2009; 2(6): 1049-10. 